\title{
El norte de México: historia ambiental a la carta
}

Reynaldo de los Reyes Patiño ${ }^{1}$

\section{BOOK REVIEW}

Juana Elizabeth Salas Hernández y Margil de Jesús Canizales Romo (Coordinadores). Historia ambiental en el norte de México (México: Universidad Autónoma de Zacatecas, El Colegio de San Luis. 2020). 


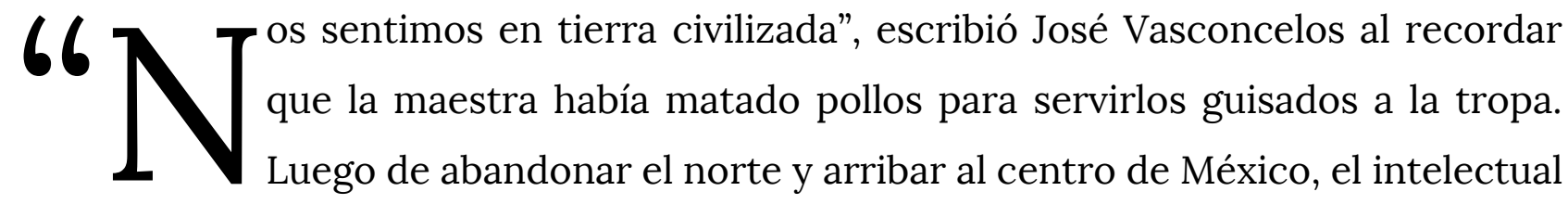
oaxaqueño dejó atrás la "carne asada" y la "barbarie" para entrar en la tierra de los guisos. Narrado en La tormenta, este episodio es un lugar común para referir la idea de la escasa "cultura" del norte mexicano, que junto con la de una escasa "naturaleza" derivada de su árido territorio, han creado la imagen de un espacio vacío y desértico.

La idea, por supuesto, no debe tomarse muy en serio, como lo muestra el libro Historia ambiental en el norte de México, coordinado por Juana Elizabeth Salas Hernández y Margil de Jesús Canizales Romo, profesores de la Universidad Autónoma de Zacatecas. Partiendo de algunos referentes historiográficos como Cynthia Radding, Micheline Cariño y Carlos Valdés, los 9 capítulos y 13 autores del libro exponen que el periodo colonial no significó la ocupación de un espacio vacío, sino de un territorio con de numerosos grupos indígenas con gran movilidad y amplio conocimiento del entorno natural. En este sentido, la imposición de un nuevo sistema productivo, el hispánico, implicó no sólo la reducción de esa movilidad, sino la transformación del paisaje norteño, donde hasta ahora permanecen superpuestos los indicios de un legado indígena y colonial.

Los primeros tres capítulos del libro toman como eje a los grupos y territorios indígenas. Juan Carlos Ruiz Guadalajara analiza cómo tras la expansión de la frontera hispánica, en un espacio habitado por los indígenas guachichiles, un modelo energético agroganadero y protoindustrial requirió de grandes cantidades de madera y carbón vegetal, creando nuevas redes de intercambio y espacios con relaciones laborales pluriétnicas. Mientras que los guachichiles fueron desplazados e incorporados a una nueva dinámica colonial, Cynthia Radding muestra en su capítulo cómo otros grupos como los yoremem lograron mantenerse con más éxito en su territorio, produciendo paisajes culturales que pueden leerse "en la tierra misma, en los documentos escritos, en los restos culturales de antaño, y en los mapas e imágenes" (p. 57), a pesar de que fueron silenciados por documentos misionales. Como mencionan en su capítulo Adi Estela Lazos Ruiz y Claudio Garibay Orozco, ese silencio se sigue manifestando en la historiografía oficial, y para compensarlo los autores resaltan el legado de los 
chichimecas señalando cómo esos grupos formaron paisajes que influyeron en rutas y asentamientos que aún hoy pueden distinguirse.

Los siguientes tres capítulos, aunque con diferentes perspectivas, tienen a la minería como su objeto central. Tomando el caso de Mazapil, Juana Salas muestra cómo un lugar caracterizado por "la esterilidad de la tierra y la riqueza de sus minerales" (p. 93) se vio transformado por la minería, por los asentamientos y por el reparto y cultivo de tierras que formaron un "paisaje hispanizado". Por su parte, el capítulo de Miguel Aguilar-Robledo, José Antonio Ávalos-Lozano y María Gabriela Torres Montero, reseña la explotación minera entre los siglos XVIII y XIX desde una perspectiva cercana a la historia de la ciencia y la tecnología; la lectura de este trabajo resulta difícil no sólo por los tecnicismos, sino porque carece de un argumento claro y parece más bien un conjunto de notas. El otro capítulo de este grupo, escrito por Ávalos-Lozano, AguilarRobledo y Gerardo Hernández Cendejas, ofrece un bosquejo del beneficio de la plata y de sus efectos sobre la salud durante los mismos años; en él los autores exponen que los científicos, las autoridades y algunos sectores de la sociedad eran conscientes de los riesgos de esa actividad sobre la salud y el ambiente, atribuyendo la escasez de regulaciones a "intereses económicos egoístas y de corto plazo" (p. 148).

Los últimos tres capítulos, podríamos decir, son una miscelánea que dialoga bien con el resto del libro. Evelyn Alfaro Rodríguez y Efrén Zapata Martínez sostienen en su estudio que el establecimiento de la ciudad minera de Zacatecas provocó una serie de reacciones ecológicas en cadena que disminuyeron la vegetación de los cerros circundantes a la ciudad, produjeron inundaciones y contribuyeron a la escasez de agua. Por otra parte, el capítulo de Francisco Montoya Mar señala cómo impactó la introducción de caña de azúcar en la región del Valle de Juchipila, en el siglo XVII, y argumenta que la producción de piloncillo se volvió un símbolo de identidad regional que se mantiene hasta hoy. Por último, un estudio arqueológico de Angélica María Medrano nos remite a tiempos prehispánicos para estudiar los restos de moluscos encontrados en la región caxcana, al sur de Zacatecas; la autora sostiene que éstos pueden considerarse indicadores de jerarquización social entre la población, pues su obtención implicó extensas redes de intercambio. 
Como puede verse, el libro presenta un buen servicio a la carta y ofrece una variedad de temas que incluyen análisis sobre asentamientos indígenas y españoles, espacios mineros, agrícolas y de explotación forestal. No puedo, sin embargo, negar la cruz de mi parroquia: se extrañó un capítulo dedicado exclusivamente a la ganadería, otra actividad fundamental para entender la transformación del paisaje norteño, y que además ha producido ya buenas investigaciones de historia ambiental, tanto para el país como para la región. ${ }^{2}$ Dejando este faltante de lado, el libro presenta también una buena variedad de enfoques, y debe destacarse el esfuerzo por integrar trabajos con vocación interdisciplinaria. La antropología y la etnografía ya tienen carta de ciudadanía dentro de la historia ambiental, y los capítulos de Ruiz y Radding son ejemplo de ello. De la arqueología, por su parte, aún tenemos mucho que aprender, y por eso debe agradecerse el trabajo de Medrano, aunque a veces cueste trabajo entender la jerga de la disciplina. ${ }^{3}$

Dentro de la historiografía ambiental mexicana, este libro se suma a otros trabajos colectivos que estudian el desarrollo histórico de una región desde una mirada ambiental. ${ }^{4}$ Desafortunadamente, los coordinadores del libro parecen haber sido víctimas del apremio editorial, ya que la recapitulación historiográfica de su introducción tiene deficiencias importantes, y junto con algunos capítulos, tiene descuidos que le restan calidad. Se extrañó, sobre todo, que ofrecieran un argumento central que profundizara en el debate en torno a la dimensión ambiental de los procesos de "fronterización" ocurridos a lo largo y ancho del imperio español. ${ }^{5}$ En el libro se presentan también otras líneas de investigación relevantes pero que no acabaron de cuajar, por lo que esperemos que estos u otros autores puedan retomarlas. Al final de cuentas, esta obra cumple con abrir nuevas rutas de investigación y con mostrarnos un

\footnotetext{
${ }^{2}$ Melville, A plague of sheep: environmental consequences of the conquest of Mexico; Hernández, Historia ambiental de la ganadería en México; Perramond, Political Ecologies of Cattle Ranching in Northern Mexico: Private Revolutions.

${ }_{3}^{3}$ Una jerga, eso sí, que evocando al glíglico, permite aprender mucho de los ecofactos malacofaunales -bivalvos y univalvos-, tales como las cuentas y pendientes obtenidos de la charnela del pelecípodo, o los faldellines fabricados con gasterópodos.

${ }^{4}$ Desprendido de la historiografía agraria francesa, el referente principal en esto sigue siendo Tortolero Villaseñor, Tierra, agua y bosques: historia y medio ambiente en el México central. Un libro más reciente, y más cercano a un enfoque multidisciplinario, es Cañedo Gamboa y Radding, Historia, medio ambiente y áreas naturales protegidas en el centro-norte de México. Contribuciones para la ambientalización de la historiografía mexicana, siglos XVIII-XXI.

5 Un debate que, por cierto, tiene ya una sólida base en Radding, Landscapes of Power and Identity. Comparative Histories in the Sonoran Desert and the Forests of Amazonia from Colony to Republic.
} 
norte de México menos vacío y desértico, así como una historiografía ambiental cada vez más fértil, pero que aún debe seguirse cocinando.

\section{REFERENCES}

Cañedo Gamboa, Sergio Alejandro, y Cynthia Radding, eds. Historia, medio ambiente y áreas naturales protegidas en el centro-norte de México. Contribuciones para la ambientalización de la historiografía mexicana, siglos XVIII-XXI. San Luis Potosí: El Colegio de San Luis, 2016.

Hernández, Lucina, ed. Historia ambiental de la ganadería en México. Xalapa, Veracruz: Instituto de Ecología; L'Institut de Recherche pour le Développement, 2001.

Melville, Elinor G. K. A plague of sheep: environmental consequences of the conquest of Mexico. Studies in environment and history. New York: Cambridge University, 1994.

Perramond, Eric. Political Ecologies of Cattle Ranching in Northern Mexico: Private Revolutions. Society, Environment, and Place. University of Arizona Press, 2010.

Radding, Cynthia. Landscapes of Power and Identity. Comparative Histories in the Sonoran Desert and the Forests of Amazonia from Colony to Republic. Durham: Duke University Press, 2005.

Tortolero Villaseñor, Alejandro, ed. Tierra, agua y bosques: historia y medio ambiente en el México central. Ciudad de México: Centre français d'études mexicaines et centraméricaines, Instituto de Investigaciones Dr. José María Luis Mora, Potrerillos Editores, Universidad de Guadalajara, 1996. 